\title{
Methyldopa in Treatment of Hypertension Due to Chronic Renal Disease
}

\author{
R. G. LUKE*, M.B., M.R.C.P., M.R.C.P.ED., A. C. KENNEDY†, M.D., F.R.C.P.ED., M.R.C.P.GLASG.
}

Brit. med. F., 1964, 1, 27-30

The use of methyldopa in essential hypertension has been described in several recent publications (Irvine et al., 1962; Dollery and Harington, 1962 ; Bayliss and Harvey-Smith, 1962 ; Daley and Evans, 1962). Methyldopa is a decarboxylase inhibitor which interferes with the formation of dopamine, the precursor of noradrenaline, from dopa, but the relation of this action to its hypotensive effect is not yet firmly established. Most published work suggests that renal function does not deteriorate as the blood-pressure is lowered with methyldopa, and, indeed, Onesti et al. (1962) reported reduction of renal vascular resistance after intravenous methyldopa, an effect opposite to that obtained with ganglion-blockers and guanethidine. We were thus interested to see whether methyldopa would prove useful in the treatment of the hypertension resulting from chronic renal disease.

\section{Material and Methods}

Of the 21 patients studied, 13 had chronic glomerulonephritis, four chronic pyelonephritis, three polycystic kidneys, and one renal artery stenosis with nephrosclerosis. Further clinical details are given in the Table. Patients were under observation before treatment for periods varying from two weeks to three years. Pretreatment data are based on many observations and all patients were initially in hospital. Blood-pressures were estimated both lying and standing. The systolic blood-pressures before treatment ranged from 150 to $250 \mathrm{~mm}$. Hg and the diastolic pressures from 110 to $170 \mathrm{~mm}$. $\mathrm{Hg}$. Renal function was assessed by frequent determination of the blood urea ("Technicon" autoanalyser) and periodic estimation of endogenous creatinine clearance (Hare, 1950). The bloodurea levels before treatment ranged from 37 to $295 \mathrm{mg} . / 100 \mathrm{ml}$. and the creatinine clearances from 85 to $8 \mathrm{ml} . /$ minute ; in 17 of the 21 patients studied the creatinine clearance was $60 \mathrm{ml}$./ minute or less.

Methyldopa was given initially in a dose of $250 \mathrm{mg}$. b.d. ( $250 \mathrm{mg}$. daily if severely uraemic) and gradually increased in divided doses (up to four times a day) to a total of $2 \mathrm{~g}$./day. If control was still unsatisfactory then bendrofluazide in a dosage of $5 \mathrm{mg}$. daily was also given. After discharge the patients were observed at frequent intervals (at first usually weekly). In the more severely uraemic patients moderate protein restriction ( $20-40 \mathrm{~g}$. protein/day) was instituted.

\section{Initial Control}

\section{Results}

Initial control signifies that the blood-pressure was thought to be controlled adequately or when the best possible control had been achieved. Control is arbitrarily defined as adequate if the blood-pressure has been reduced to a normal range or to not more than $100 \mathrm{~mm}$. diastolic either on standing or on lying. Adequate control was achieved in 19 of the 21 cases, including three patients with malignant hypertension and grade IV fundi and three with grade III fundal changes. There was striking

\footnotetext{
- Medical Registrar, the University Department of Medicine, the Royal Infirmary. Glasgow.

† Senior Lecturer in Medicine, the University Department of Medicine, the Royal Infirmàry, Glasgow.
}

visual improvement in two of the patients with malignant hypertension (Cases 4 and 18) within a few days of starting the drug. Relief of headache and improved effort tolerance were experienced by most of the patients. In Case 21 there was prompt relief of mental confusion as the diastolic blood-pressure fell from $170 \mathrm{~mm}$. $\mathrm{Hg}$ to normal. The time required for adequate control of the blood-pressure varied from a week or less in 14 cases to three weeks. The initial controlling dosage ranged from 0.5 to $2 \mathrm{~g}$./day ; in one patient receiving $2 \mathrm{~g}$./day, bendrofluazide was also required.

In two patients the initial control of blood-pressure was not satisfactory. In Case 19 although the diastolic blood-pressure fell substantially it proved impossible to achieve a consistent diastolic pressure at or near $100 \mathrm{~mm}$. Hg without causing troublesome postural hypotension. In Case 17 the bloodpressure response fluctuated from postural hypotension to a fairly high diastolic level ; there was symptomatic deterioration and the drug was discontinued after four weeks.

In 17 of the 19 patients in whom adequate blood-pressure control was achieved no deterioration of renal function resulted in the initial period of treatment. One patient, who had malignant hypertension associated with chronic glomerulonephritis (Case 5), showed some deterioration of renal function, and in another (Case 1) the creatinine clearance fell from 22 to $20 \mathrm{ml} . / \mathrm{min}$. Of the two patients where blood-pressure control was not adequate, one (Case 17) had a definite fall in creatinine clearance. Guanethidine had previously been stopped in this patient because of a marked deterioration of renal function.

Side-effects were relatively frequent, but only in one patient (Case 17) did they contribute to withdrawal of the drug. Drowsiness was invariable initially, but except in one patient (Case 9) it disappeared after a few days. Dryness of the mouth was also very common but did not prove especially troublesome. In two patients nightmares occurred, but they did not persist.

\section{Follow-up}

Ten patients have been followed for 6 to 12 months and a further six for periods of 2 to 6 months (see Table). The bloodpressure control has remained adequate (as defined above) in 14 of these 16 patients, including two with malignant hypertension; the improvement in the fundi of these two patients was dramatic, with resolution of papilloedema and clearing of exudates and haemorrhages. In Cases $1-6,8,10,11,14$, and 15 symptomatic improvement has been definite and we are in no doubt that methyldopa is a worth-while therapeutic measure in these patients. Some of the patients had no definite symptomatology attributable to hypertension per se-for example, Case 7-but they felt well on the drug. One of the patients (Case 8) whose blood-pressure control did not remain adequate (as defined above) had early papilloedema initially ; this cleared, the diastolic blood-pressure was considerably lowered, and the patient was working and feeling well.

Renal function has been maintained or improved in 10 of these 16 patients. One of these 10 patients (Case 12) had, as well as marked renal disease, severe chronic asthmatic bronchitis and died from bronchopneumonia after the blood-pressure had been controlled for four months. 
Renal function has deteriorated gradually in the two patients (Cases 4 and 5) with malignant hypertension due to chronic glomerulonephritis, in the two patients (Cases 9 and 13) with biopsy evidence of proliferative glomerulonephritis, and slightly (creatinine clearance from 22 to $20 \mathrm{ml} . / \mathrm{min}$.) in one of the patients with chronic pyelonephritis (Case 1). In the patient with renal-artery stenosis renal function also deteriorated while on methyldopa but improved after nephrectomy, which lowered his blood-pressure to near normal.

In 11 of the 16 patients continuing with the drug an increased dosage has been necessary to maintain reduction in bloodpressure. However, in one patient (Case 3) satisfactory bloodpressure control has been achieved for 11 months by $0.5 \mathrm{~g}$. of the drug daily. Although the dosage requirements have tended to increase, so far no patient who was initially responsive to the drug has become entirely resistant to its action except Case 9 after steroid therapy. In seven patients bendrofluazide has been given along with methyldopa with definite potentiation of hypotensive effect; in one patient (Case 6) this necessitated a reduction in dosage from 2 to $1.25 \mathrm{~g}$.

Side-effects have not so far been troublesome on long-term follow-up. Dryness of the mouth associated with an unpleasant taste has been common but not severe. Mild depression occurred for a few days in Case 8. One patient (Case 12) developed oedema, not associated with hypoalbuminaemia or cardiac failure; this responded to bendrofluazide. Another patient (Case 1) has put on $7 \mathrm{lb}$. $(3.2 \mathrm{~kg}$.) in weight since starting the drug although there are no clinical signs of fluid retention.

\section{Discussion}

Chronic renal disease leading to hypertension and thereby to progression of the renal lesion is a familiar sequence of events. In some cases the deterioration in renal function is mainly due to the continuing activity of the renal lesion per se, but in others the primary renal pathology appears to become quiescent, and secondary vascular renal damage dominates the picture and determines the fatal outcome. The importance of hypertensive vascular changes in chronic glomerulonephritis has been stressed by Volhard (1931), Ellis (1942), and Wilson (1953). Likewise in cases of chronic pyelonephritis, provided the infection in the kidney has been controlled, progression of renal damage is likely to depend on the presence of hypertension and secondary vascular changes. Moreover, patients with chronic renal disease and hypertension are much more likely to develop malignant hypertension than patients with essential hypertension; Wilson (1953) reported such a change in 32 out of 65 patients with chronic glomerulonephritis, and Brod (1956) found a $20 \%$ incidence of malignant transformation when hypertension was due to chronic pyelonephritis. In addition to these considerations, the hypertension of renal disease may merit treatment on symptomatic grounds-for example, visual deterioration and headache.

Although there are cogent reasons for attempting to control the hypertension in certain cases of chronic renal disease, there is a real danger that the fall in blood-pressure may be achieved at the expense of renal function through reduction of the glomerular filtration rate. Thus Wilson and Abrahams (1957) found in cases of chronic type I glomerulonephritis that if the blood urea was over $70 \mathrm{mg} . / 100 \mathrm{ml}$. and the creatinine clearance below $30 \mathrm{ml} . / \mathrm{min}$. renal failure progressed if the blood-pressure was lowered by ganglion-blocking drugs. Hydrallazine, which has been reported to cause improvement in renal blood-flow despite reduction in systemic blood-pressure (Moyer et al., 1951), has been recommended in such cases, but its side-effects are a major disadvantage. Reserpine and thiazide diuretics may be effeetive in controlling lesser degrees of hypertension but are usually unsuccessful if the hypertension is severe. The report by Onesti et al. (1962) of reduction of renal vascular resistance after intravenous methyldopa, together with many reports stressing the relative absence of serious side-effects and troubiesome postural hypotension, suggests that methyldopa might be superior to other hypotensive drugs for the treatment of hypertension due to renal disease ; it is our impression from the present series that this is so.

Renal function did not show any evidence of deterioration in the initial period of observation in 17 out of the 19 patients in whom good control of blood-pressure was obtained, whereas some deterioration occurred in 6 of the 16 patients followed for longer periods. This is rather similar to the experience of Hamilton and Kopelman (1963), but closer analysis of the data in our patients suggests that these results need not necessarily be interpreted as throwing doubt on the value of methyldopa in the treatment of hypertension of chronic renal disease. In two of the six patients (Cases 1 and 16) the deterioration in renal function was of relatively slight degree and was no more than might have occurred owing to the natural progression of the basic renal lesion ; indeed, in Case 1 the rate of deterioration in renal function was rather greater in the period of observation prior to methyldopa therapy. Furthermore, it could be argued that if any deterioration in renal function which occurred was due to lowering of the blood-pressure per se, one would expect it to be evident soon after the hypotensive effect was achievedthat is, within a few weeks of starting treatment-and not only after several months.

Two further patients who showed a greater degree of deterioration in renal function (creatinine clearance from 18 to $10 \mathrm{ml}$. and from 51 to $13 \mathrm{ml} . / \mathrm{min}$., both in 11 months) had malignant hypertension, and we believe that had the bloodpressure not been controlled, renal function would have deteriorated much more sharply than it did, provided of course that death had not occurred from cardiac failure or a cerebral catastrophe. The two patients (Cases 9 and 13) with biopsy evidence of proliferative glomerulonephritis and a clinical nephrotic syndrome have also shown deteriorating renal function. In Case 9, however, renal function did not alter for a two-months period during which the blood-pressure was well controlled with methyldopa; blood-pressure control was then "lost" after an unsuccessful attempt to correct the nephrotic syndrome with steroids, and thereafter renal function deteriorated. In Case 13 renal function has continued to deteriorate at least as fast in the four months after stopping methyldopa as during the four months of hypotensive therapy.

We suggest it is important to observe patients with chronic renal disease at frequent intervals and to treat hypertension when it is definitely established, even though it may still be asymptomatic, since control of the hypertension at the nonmalignant stage may reasonably be expected to delay, at least in some cases, the development of secondary vascular damage in the kidneys. Methyldopa, in view of its relative freedom from side-effects, appears to be a more suitable drug for such a therapeutic approach than other currently available hypotensive agents. However, even when renal function is more seriously impaired, reduction of blood-pressure with methyldopa can still be achieved, with resulting symptomatic benefit, without necessarily causing further deterioration of renal function.

\section{Summary}

Methyldopa was given to 21 patients with hypertension due to chronic renal disease. A short-term and a long-term assessment was made of adequacy of blood-pressure control and of the effect of hypotensive therapy on renal function. In the short-term assessment 19 of 21 patients had an adequate bloodpressure response ; in 17 of these 19 patients renal function was maintained; in only one patient did side-effects contribute towards the withdrawal of the drug. In 14 of the 16 patients followed for from 2 to 12 months, blood-pressure control remained adequate. In 10 of the 16 patients renal function was maintained, and it is likely that the main cause of deterioration 
in renal function in the other six was progression of the intrinsic renal disease. Increase in dosage was commonly required to maintain a hypotensive effect. The indications for antihypertensive therapy in chronic renal disease are considered and it is suggested that methyldopa is at present the drug of choice for this purpose.

\section{Addendum}

Since this paper was written all the patients on long-term follow-up have been observed for a further six months, except 5 and 9, who died after three months with progressive renal failure. Of the 12 patients remaining on methyldopa, bloodpressure control has remained adequate in 11 ; a slight increase in dosage has been necessary in 5 patients; control remained less good in Case 8 and methyldopa therapy was supplemented by $10 \mathrm{mg}$. guanethidine.

Malignant hypertension with virtual blindness developed in Case 13 three months ago, by which time the creatinine clearance had fallen to $20 \mathrm{ml} . / \mathrm{min}$.; the patient now agreed to methyldopa therapy, and satisfactory control of blood-pressure with marked visual improvement was achieved and has been maintained without detectable deterioration in renal function.

Renal function has been maintained or improved in 9 of the original 12 patients remaining on methyldopa; the fall in the other three is slight (Case 8 , creatinine clearance 46 to 41 $\mathrm{ml} . / \mathrm{min}$.; Case 11,13 to $11 \mathrm{ml} . / \mathrm{min}$.; Case 14,30 to 27 $\mathrm{ml} . / \mathrm{min}$.); and there has been no further deterioration in renal function in Case 4, who had malignant hypertension.

One other side-effect of treatment was intermittent nocturnal diarrhoea, responding to symptomatic measures, in Cases 4 and 11. Fluid retention, responding to a thiazide diuretic, occurred in Cases 11 and 13.

We have also treated a further 10 patients with hypertension secondary to chronic renal disease for periods of one to six months ; satisfactory control of blood-pressure without deterioration in renal function has been achieved in seven, including one patient with malignant hypertension.

We are grateful to Professor E. M. McGirr for encouragement throughout this study, and to Miss Mary J. B. Gray, who performed the estimations of creatinine clearance.

\section{REFERENCES}

Bayliss, R. I. S., and Harvey-Smith, E. A. (1962). Lancet, 1, 763.

Brod, J. (1956). Ibid., 1, 973.

Daley, D., and Evans, B. (1962). Brit. med. F., 2, 156.

Dollery, C. T., and Harington, M. (1962). Lancet, 1, 759.

Ellis, A. (1942). Ibid., 1, 34.

Hamilton, M., and Kopelman, H. (1963). Brit. med. F., 1, 151

Hare, R. S. (1950). Proc. Soc. exp. Biol. (N.Y.), 74, 148.

Irvine, R. O. H., O'Brien, K. P., and North, J. D. K. (1962). Lancet, 1, 300.

Moyer, J. H., Handley, C. A., and Huggins, R. A. (1951). ¥. Pharmacol. exp. Ther., 103, 368.

Onesti, G., Brest, A. N., Novack, P., and Moyer, J. H. (1962). Amer. F. Cardiol., 9, 863.

Volhard, F. (1931). In Handbuch der inneren Medizin, edited by G. V. Bergmann and R. Staehelin, 2nd ed., vol. 6, Pt. 2, p. 1426. Springer, Berlin.

Wilson, C. (1953). Lancet, 2, 632.

- and Abrahams, D. G. (1957). Brit. med. Bull., 13, 39.

\title{
Hypoanabolic Hypoalbuminaemia in Gastro-intestinal Disease
}

\author{
K. N. JEEJEEBHOY*, M.B., M.R.C.P., M.R.C.P.ED.
}

Brit. med. F., 1964, 1, 30-35

Hypoalbuminaemia in gastro-intestinal disease is commonly associated with gastro-intestinal protein loss (Citrin et al., 1957 ; Gordon, 1959 ; Schwartz and Jarnum, 1959 ; Holman et al., 1959; Steinfeld et al., 1960 ; London et al., 1961 ; Davidson et al., 1961 ; Jeejeebhoy and Coghill, 1961). Patients with gastro-intestinal disease who have hypoalbuminaemia, however, do not invariably have current gastro-intestinal protein loss, and recent studies have indicated that deficient albumin synthesis alone may be an important cause of hypoalbuminaemia in some patients (Jeejeebhoy, 1962 ; Jones, 1962).

This paper describes the clinical features and studies of protein metabolism in 19 patients in whom hypoalbuminaemia associated with gastro-intestinal disease was due to deficient albumin synthesis. The results of intestinal and hepatic function tests are also given.

Reduced albumin synthesis was the chief cause of chronic hypoalbuminaemia in patients who had had a partial gastrectomy. This was the situation also in some patients suffering from idiopathic steatorrhoea and pancreatic disease, and in patients after gastro-intestinal albumin loss in ulcerative colitis, constrictive pericarditis, and Crohn's disease. The effects of treatment are described.

- West Middlesex Hospital, Isleworth, and Postgraduate Medical School of London. Present address: Atomic Energy Establishment
Richardson and Cruddas Building, Byculla, Bombay 8, India.
Serum Protein Estimation.-Total protein was estimated by the biuret reaction (Weichselbaum, 1946), using an autoanalyser as described in the Autoanalyser Technical Bulletin. Serum albumin was estimated by the HABA (2-[4'-hydroxybenzeneazo] -benzoic acid) dye method (Rutstein et al., 1954), using an autoanalyser calibrated against known standards of crystalline human albumin. Serum globulin was obtained by subtracting the value for serum albumin from that of the total serum protein. Electrophoresis of serum protein was performed on cellulose acetate and the strips were stained with Ponceau red.

Albumin turnover studies were carried out using the method described previously (Jeejeebhoy and Coghill, 1961 ; Jeejeebhoy, 1962). Radioiodinated human serum albumin (R.I.H.S.A.) was prepared by the method of McFarlane (1958). The patients were given Lugol's iodine and "amberlite IRA-400 (a)" by mouth for two days beforehand and throughout the period of observation. R.I.H.S.A. was injected intravenously and blood was taken into heparin 10 minutes after the injection and daily for between 7 and 14 days. Daily 24-hour urine and three-day stool collections were made.

Total exchangeable albumin (T.E.A.) is the body albumin, vascular and extravascular, in which the tracer is distributed. The value for the T.E.A. is obtained by adding the intravascular 